Jurnal Talenta Sipil, 2(2), Agustus 2019, pp. 44-49

Publisher by Program Studi Teknik Sipil Fakultas Teknik Universitas Batanghari Jl. Slamet Ryadi, Broni-Jambi Kecamatan Telanaipura Kodepos: 36122

ISSN 2615-1634 (Online)

\title{
Analisis Perhitungan Waktu pada di Pekerjaan Irigasi Melawai dengan Metode CPM
}

\author{
${ }^{1}$ Elvira Handayani, ${ }^{2}$ Annisaa Dwiretnani, ${ }^{3}$ Kurniawan A. \\ ${ }^{1,2}$ Dosen Fakultas Teknik Sipil Universitas Batanghari Jambi \\ ${ }^{3}$ Mahasiswa Teknik Sipil Universitas Batanghari Jambi \\ Email : Elvira.handayani@yahoo.co.id
}

\begin{abstract}
Abstrak
Manajemen Konstruksi meliputi mutu fisik konstruksi, biaya dan waktu. manajemen material dan manjemen tenaga kerja yang akan lebih ditekankan. Hal itu dikarenakan manajemen perencanaan berperan hanya 20\% dan sisanya manajemen pelaksanaan termasuk didalamnya pengendalian biaya dan waktu proyek. Normalisasi sungai adalah suatu metode yang digunakan untuk menyediakan alur sungai dengan kapasistas mencukupi untuk menyalurkan air, terutama air yang berlebih saat curah hujan tinggi. Tujuan normalisasi sungai antara lain untuk keperluan navigasi, melindungi tebing sungai karena erosi (kikisan), atau untuk memperluas profil sungai guna menampung banjir-banjir yang terjadi. Proyek normalisasi sungai mencakup pengerasan dinding sungai, pembangunan sudetan, pembuatan tanggul dan juga pengerukan. Pengerasan atau penguatan tebing sungai dilakukan dengan pembetonan dinding atau dengan pemasangan batukali, sudetan dilakukan dengan membuat sungai baru yang lurus dengan lintasan terpendek. Sedangkan pembuatan tanggul dilakukan dengan timbunan tanah atau dengan dinding beton yang dipasang memanjang di lokasi-lokasi bergeografi rendah yang rawan banjir.
\end{abstract}

Kata kunci: perhitungan waktu; irigasi; CPM

\section{PENDAHULUAN}

Tuntutan pembangunan di segala bidang semakin dirasakan, terutama dikota yang sedang berkembang, hal ini dilakukan dalam rangka meningkatkan taraf hidup rakyatnya. Banyaknya pembangunan yang harus dikejar, ketinggalan ini diusahakan harus dikejar dengan pembangunan di segala bidang. Proyek pada umumnya memiliki batas waktu (deadline), artinya proyek harus diselesaikan sebelum atau tepat pada waktu yang telah ditentukan. Berkaitan dengan masalah proyek ini maka keberhasilan pelaksanaan sebuah proyek tepat pada waktunya merupakan tujuan yang penting baik bagi pemilik proyek maupun kontraktor. Demi kelancaran jalannya sebuah proyek dibutuhkan manajemen yang akan mengelola proyek dari awal hingga proyek berakhir, yakni manajemen proyek.

Kabupaten Tanjung Jabung Barat di Provinsi Jambi saat ini dalam tahap pembangunan normalisasi sungai adalah suatu metode yang digunakan untuk menyediakan alur sungai dengan kapasistas memadai untuk menyalurkan air, terutama air yang berlebih saat curah hujan tinggi.dengan menormalisasi sungai yang merupakan pemasok utama daerah irigasi melawai menjadi perhatian dari pemerintah Kabupaten Tanjung Jabung Barat,dan diselaraskan dengan kegiatan peningkatan saluran irigasi yang merupakan satu-satunya di daerah kecamatan melawai.

Seperti yang kita ketahui bersama bahwa untuk membangun suatu sarana normalisasi sungai dalam peningkatan saluran irigasi memerlukan dana yang tidak sedikit contohnya saja peningkatan irigasi yang dilaksanakan di Kabupaten.Tanjung Jabung Barat,untuk melakukan peningkatan ini diperlukan perencanaan SDA (Sumber Daya Air) yang optimal dan memenuhi syarat teknis menurut fungsi, volume maupun sifatnya sehingga pembangunan kontruksi tersebut dapat berguna maksimal bagi perkembangan daerah sekitarnya.

Oleh karena itu diperlukan suatu peneltitian apa hasil dari penerapan metode CPM (Critical Path Methode).

Proyek normalisasi sungai mencakup pengerasan dinding sungai, pembangunan sudetan, pembuatan tanggul dan juga pengerukan. Pengerasan atau penguatan tebing sungai 
dilakukan dengan pembetonan dinding atau dengan pemasangan batukali, sudetan dilakukan dengan membuat sungai baru yang lurus dengan lintasan terpendek. Sedangkan pembuatan tanggul dilakukan dengan timbunan tanah atau dengan dinding beton yang dipasang memanjang di lokasi-lokasi bergeografi rendah yang rawan banjir. Menciptakan kondisi sungai dengan lebar dan kedalaman tertentu.Sungai mampu mengalirkan air sehingga tidak terjadi luapan dari sunga itersebut.

Kegiatan normalisasi sungai berupa membersihkan sungai dari endapan lumpur dan memper dalamnya agar kapasitas sungai dalam menampung air dapat meningkat. Hal ini dilakukan dengan cara mengeruk sungai tersebut di titik-titik rawan tersembunyi aliran air upaya pemulihan lebar sungai merupakan bagian penting dari program normalisasi sungai karena meningkatkan kapasitas sungai dalam menampung dan mengalirkan kelaut. Menurut Maryono dalam Masyhuri (2007) pengembangan sungai-sungai di Indonesia dalam 30 tahun terakhir ini mengalami peningkatan pembangunan fisik yang relative cepat. Pembangunan fisik tersebut misalnya pembuatan sudetan, pelurusan, pembuatan tanggul sisi dan pembetonan tebing, baik sungai kecil maupun besar.

\section{Landasan Teori \\ Analisa Waktu}

Tujuan analisa waktu adalah untuk mengetahui saat mulai dan saat selesai pelaksanaan setian pekerjaan, sehingga bila terjadi keterlambatan bias diketahui bagaimana pengaruhnya dan selanjutnya ditetapkan tindakan apa yang harus diambil.

\section{Network Planning}

Adalah hubungan ketergantungan antara bagian-bagian pekerjaan yang digambarkan dalam diagram Network. Dengan demikian diketahui bagian-bagian pekerjaan mana yang harus didahulukan, pekerjaan mana yang menunggu selesainya pekerjaan yang lain, pekerjaan mana yang tidak perlu tergesa-gesa sehingga alat dan sumber daya manusia dapat digeser ke pekerjaan lain untuk efisiensi.

\section{CPM (Critical Path Method)}

Suatu metode untuk merencanakan dan mengawasi proyekproyek merupakan sistem yang paling banyak dipergunakan diantara semua sistem lain yang memakai prinsip pembentukan jaringan.

Pengertian CPM Menurut Levin dan Kirkpatrick (1995), metode Jalur Kritis (Critical Path Method - CPM), yakni metode untuk merencanakan dan mengawasi proyekproyek merupakan sistem yang paling banyak dipergunakan diantara semua sistem lain yang memakai prinsip pembentukan jaringan. Dengan CPM, jumlah waktu yang dibutuhkan untuk menyelesaikan berbagai tahap suatu proyek dianggap diketahui dengan pasti, demikian pula hubungan antara sumber yang digunakan dan waktu yang diperlukan untuk menyelesaikan proyek. CPM adalah model manajemen proyek yang mengutamakan biaya sebagai objek yang dianalisis (Siswanto, 2007). CPM merupakan analisa jaringan kerja yang berusaha mengoptimalkan biaya total proyek melalui pengurangan atau percepatan waktu penyelesaian total proyek yang bersangkutan. Jaringan Kerja Network planning (Jaringan Kerja) pada prinsipnya adalah hubungan ketergantungan antara bagian-bagian pekerjaan yang digambarkan atau divisualisasikan dalam diagram network. Dengan demikian dapat dikemukakan bagian-bagian pekerjaan yang harus didahulukan, sehingga dapat dijadikan dasar untuk melakukan pekerjaan selanjutnya dan dapat dilihat pula bahwa suatu pekerjaan belum dapat dimulai apabila kegiatan sebelumnya belum selesai dikerjakan. 


\section{METODE}

Penelitian dilaksanakan selama 3 bulan mulai dari persiapan ,Survei lapangan ,analisis rencana anggaran biaya(RAB) sampai penyusunan hasil akhir pekerjaan.

Ada beberapa teknik pengumpulan data sebagai berikut:

1. Teknik kepustakaan

Yaitu teknik pengumpulan data dengan cara membaca buku-buku literatur dan sumbersumber dari kepustakaan.

2. Teknik interview

Yaitu pengumpulan data dengan cara mengadakan pertanyaan secara lisan.

3. Observasi

Yaitu dengan cara memperoleh dokumen-dokumen yang mencakup data variable yang bentuk tulisan atau lisan.

Studi pendahuluan merupakan studi yang dilakukan untuk mempertajam arah studi utama. Studi pendahuluan dilakukan dengan tujuan utama untuk menghimpun berbagai informasi yang diperlukan dalam pelaksanaan penelitian. Hal ini perlu dilakukan, mengingat informasi yang relavan dapat menunjang keberhasilan penelitian terutama karena hasil studi pendahuluan ini dapat menjadi acuan dalam suatu penelitian.

Pengumpulan data dalam penelitian ini ada banyak cara mulai dari mengumpulkan data skunder dan data Primer, maksudnya adalah data-data yang diperoleh secara tidak langsung melainkan perantara. Data skunder ini dapat berupa buku-buku, jurnal penelitian, artikelartikel, catatan, internet atau laporan baik yang dipublikasikan dan yang tidak dipublikasikan hingga studi kepustakaan guna untuk mendukung penyelesaian penelitian ini sedangkan data primer berupa pengumpulan data diperoleh secara langsung dalam hal ini dilakukan dengan cara wawancara dan observasi secara langsung .

Analisa data adalah upaya atau cara, data yang telah terkumpul melalui kegiatan pengumpulan data belum mempunyai arti dan tujuan penelitian.

\section{HASIL}

\section{Memberikan Kode Tiap Pekerjaan (Menginventarisasi Pekerjaan)}

Langkah pertama yang dilakukan dalam menyusun jaringan kerja (network planning) adalah menginventariskan Pekerjaan. yaitu dengan cara pengkajian dan pengindefikasian lingkup proyek, menguraikan atau memecahkannya menjadi kegiatan-kegiatan pada proyek. Kegiatan-kegiatan Peningkatan/Rehab Jaringan Daerah Irigasi Melawai Kec. Tungkal Ulu dapat terlihat pada tabel 1. dibawah ini:

\section{Tabel 1. Urutan Pekerjaan (Kegiatan Pekerjaan)}

\begin{tabular}{clc}
\hline No & \multicolumn{1}{c}{ Jenis Kegiatan } & Kode \\
\hline A & Pekerjaan Pendahuluan & \\
1 & Pengukuran dan Pematokan Lokasi & AA \\
2 & Pekerjaan Barak Kerja & AB \\
3 & Pembuatan papan nama proyek & AC \\
4 & Mobilisasi dan Demobilisasi & AD \\
5 & Pembuatan Laporan dan Dokumentasi & AE \\
B & Pekerjaan Normalisasi & \\
6 & Penyiapan tebang tebas pembersihan lokasi & BA \\
7 & Pekerjaan galian menggumakan alat & BB \\
8 & Pekerjaan pembuatan hasil galian dengan cara manual & BC \\
C & Pekerjaan Beronjong & \\
9 & Pekerjaan Beronjong & CA \\
10 & Pekerjaan pondasi cerucuk/dolken & CB \\
D & Pekerjaan Rehap Pintu Air dan Atap & \\
11 & Pekerjaan rangka kuda-kuda kayu 5/7 & DA \\
12 & Pekerjaan kasau atap kayu $3 / 4$ & DB \\
\hline
\end{tabular}




\begin{tabular}{clc}
\hline No & \multicolumn{1}{c}{ Jenis Kegiatan } & Kode \\
\hline 13 & Pekerjaan atap seng gelombang & DC \\
14 & Pekerjaan bubungan & DD \\
15 & Pekerjaan lisplank kayu 2/20 & DE \\
16 & Pekerjaan besi pintu air utama & DF \\
\hline
\end{tabular}

Sumber : Data Olahan (2018)

\section{Menentukan Perkiraan Waktu (Durasi) Pekerjaan Proyek.}

Langkah ini adalah menentukan perkiraan kurun waktu bagi setiap kegiatan yang ada pada Pembangunan rehab irigasi melawai yang berlokasi di Melawai Kec.Tungkal Ulu terlihat pada tabel 2 dibawah ini:

Tabel.2. Durasi Pekerjaan (Kegiatan Pekerjaan)

\begin{tabular}{|c|c|c|c|}
\hline No & Jenis Kegiatan & Kode & Durasi (hari) \\
\hline $\mathbf{A}$ & Pekerjaan Pendahuluan & & \\
\hline 1 & Pengukuran dan Pematokan Lokasi & AA & 5 \\
\hline 2 & Pekerjaan Barak Kerja & $\mathrm{AB}$ & 5 \\
\hline 3 & Pembuatan papan nama proyek & $\mathrm{AC}$ & 5 \\
\hline 4 & Mobilisasi dan Demobilisasi & $\mathrm{AD}$ & 27 \\
\hline 5 & Pembuatan Laporan dan Dokumentasi & $\mathrm{AE}$ & 89 \\
\hline $\mathbf{B}$ & Pekerjaan Normalisasi & & \\
\hline 6 & Penyiapan tebang tebas pembersihan lokasi & BA & 5 \\
\hline 7 & Pekerjaan galian menggumakan alat & $\mathrm{BB}$ & 54 \\
\hline 8 & Pekerjaan pembuatan hasil galian dengan cara manual & $\mathrm{BC}$ & 28 \\
\hline $\mathbf{C}$ & Pekerjaan Beronjong & & \\
\hline 9 & Pekerjaan Beronjong & $\mathrm{CA}$ & 56 \\
\hline 10 & Pekerjaan pondasi cerucuk/dolken & $\mathrm{CB}$ & 14 \\
\hline D & Pekerjaan Rehap Pintu Air dan Atap & & \\
\hline 11 & Pekerjaan rangka kuda-kuda kayu 5/7 & DA & 7 \\
\hline 12 & Pekerjaan kasau atap kayu 3/4 & DB & 7 \\
\hline 13 & Pekerjaan atap seng gelombang & DC & 7 \\
\hline 14 & Pekerjaan bubungan & DD & 7 \\
\hline 15 & Pekerjaan lisplank kayu 2/20 & $\mathrm{DE}$ & 7 \\
\hline 16 & Pekerjaan besi pintu air & DF & 56 \\
\hline
\end{tabular}

Sumber : Data olahan (2018)

\section{Menyusun Setiap Hubungan Kegiatan}

Dalam jaringan kerja (network planning), menyusun komponen-komponen sesuai dengan urutan logika ketergantungannya merupakan dasar pembuatan jaringan kerja, sehingga diketahui urutan kegiatan dari awal mulainya proyek sampai dengan selesainya proyek secara keseluruhan.

Dalam pembuatan jaringan kerja (network planning), ada beberapa kemungkinan yang dapat terjadi dari hubungan antar kegiatan yang disusun menjadi mata rantai urutan kegiatan yang sesuai dengan logika ketergantungan yaitu :

a. Suatu kegiatan dapat dikerjakan secara bersamaan dengan kegiatan yang lainnya.

b. Suatu kegiatan dapat dikerjakan apabila kegiatan sebelumnya telah selesai dikerjakan.

c. Suatu kegiatan dapat dikerjakan secara tersendiri tanpa harus menunggu kegiatan sebelumnya.

Urutan kegiatan-kegiatan yang sesuai dengan logika ketergantungan pada Rehab jaringan irigasi melawai, seperti pada tabel dibawah ini : 
Tabel 3. Daftar Kegiatan-Kegiatan Pengikut Dan Pendahulu

\begin{tabular}{clccc}
\hline No & \multicolumn{1}{c}{ Jenis Kegiatan } & Kode & $\begin{array}{c}\text { Predecessor } \\
\text { (Pendahulu) }\end{array}$ & $\begin{array}{c}\text { Sucessor } \\
\text { (Pengikut) }\end{array}$ \\
\hline A & Pekerjaan Pendahuluan & & & \\
1 & Pengukuran dan Pematokan Lokasi & AA & - & AC \\
2 & Pekerjaan Barak Kerja & AB & - & AC \\
3 & Pembuatan papan nama proyek & AC & AA,AB & AD \\
4 & Mobilisasi dan Demobilisasi & AD & AC & BA,BB \\
5 & Pembuatan Laporan dan Dokumentasi & AE & DF & - \\
B & Pekerjaan Normalisasi & & & \\
6 & Penyiapan tebang tebas pembersihan lokasi & BA & AD & BC \\
7 & Pekerjaan galian menggumakan alat & BB & AD & CA \\
8 & Pekerjaan pembuatan hasil galian dengan cara manual & BC & BA,BB & CB \\
C & Pekerjaan Beronjong & & & \\
9 & Pekerjaan Beronjong & CA & BB & CB \\
10 & Pekerjaan pondasi cerucuk/dolken & CB & BC,CA & DA \\
D & Pekerjaan Rehap Pintu Air dan Atap & & & \\
11 & Pekerjaan rangka kuda-kuda kayu 5/7 & DA & CB & DB \\
12 & Pekerjaan kasau atap kayu 3/4 & DB & DA & DC \\
13 & Pekerjaan atap seng gelombang & DC & DB & DD \\
14 & Pekerjaan bubungan & DD & DC & DE \\
15 & Pekerjaan lisplank kayu 2/20 & DE & DD & DF \\
16 & Pekerjaan besi pintu air & DF & DE & AE \\
\hline St & Deka ODa & & &
\end{tabular}

Sumber : Data Olahan (2018)

\section{Mengindentifikasi Jalur Kritis, Total Float, Waktu Penyelesaian Proyek}

Yang dimaksud dengan jalur ktitis pada langkah ini adalah jalur kritis pada langkah ini adalah jalur yang terdiri dari rangkaian dalam lingkup proyek, yang apabila terlambat akan mengakibatkan keterlambatan proyek secara keseluruhan kegiatan yang berada dalam jalur ini disebut sebagai kegiatan kritis. Sedangkan Float adalah tenggang waktu suatu kegiatan tertentu yang non kritis dari Proyek peningkatan jaringan irigasi melawai.

Tabel 4. Tabel Total Float

\begin{tabular}{|c|c|c|c|c|c|c|c|c|}
\hline \multirow[b]{2}{*}{ No } & \multirow{2}{*}{$\begin{array}{c}\text { Kode } \\
\text { Kegiatan }\end{array}$} & \multirow{2}{*}{$\begin{array}{c}\text { Waktu } \\
\text { Hari }\end{array}$} & \multicolumn{2}{|c|}{ Perhitungan Maju } & \multicolumn{2}{|c|}{ Perhitungan Mundur } & \multirow[b]{2}{*}{ Total Float } & \multirow[b]{2}{*}{ Keterangan } \\
\hline & & & $\mathbf{E S}$ & EF & $\mathbf{L S}$ & $\mathbf{L F}$ & & \\
\hline 1 & AA & 5 & 0 & 5 & 5 & 0 & 0 & Kritis \\
\hline 2 & $\mathrm{AB}$ & 5 & 5 & 10 & 5 & 5 & 0 & Kritis \\
\hline 3 & $\mathrm{AC}$ & 5 & 10 & 15 & 10 & 10 & 0 & Kritis \\
\hline 4 & $\mathrm{AD}$ & 27 & 15 & 42 & 37 & 37 & 0 & Kritis \\
\hline 5 & BA & 5 & 70 & 75 & 65 & 42 & 23 & - \\
\hline 6 & $\mathrm{BB}$ & 54 & 75 & 129 & 91 & 91 & 0 & Kritis \\
\hline 7 & $\mathrm{BC}$ & 28 & 84 & 112 & 119 & 42 & 77 & - \\
\hline 8 & $\mathrm{CA}$ & 56 & 112 & 168 & 147 & 175 & 0 & Kritis \\
\hline 9 & $\mathrm{CB}$ & 14 & 168 & 182 & 161 & 161 & 0 & Kritis \\
\hline 10 & DA & 7 & 182 & 189 & 168 & 168 & 0 & Kritis \\
\hline 11 & DB & 7 & 189 & 196 & 175 & 175 & 0 & Kritis \\
\hline 12 & $\mathrm{DC}$ & 7 & 196 & 203 & 182 & 182 & 0 & Kritis \\
\hline 13 & DD & 7 & 203 & 210 & 189 & 189 & 0 & Kritis \\
\hline 14 & $\mathrm{DE}$ & 7 & 210 & 217 & 196 & 196 & 0 & Kritis \\
\hline 15 & DF & 56 & 217 & 273 & 252 & 252 & 0 & Kritis \\
\hline 16 & $\mathrm{AE}$ & 89 & 273 & 341 & 341 & 341 & 0 & Kritis \\
\hline
\end{tabular}

Sumber : Data Olahan (2018)

Dari perhitungan total float diatas, maka dapat ditentukan lintasan kritis, dimana lintasan kritis atau jalur kritis memiliki total float $=0$, sehingga dapat dijelaskan sebagai berikut : 
1. Yang memiliki total float $=0$ adalah kegiatan AA-AB-AC-AD-BB-CA-CB-DA-DB-DCDD-DE-DF-AE maka jalur ini adalah kritis.

2. Kurun waktu penyelesaian pekerjaan dengan menggunakan metode Critical Path Methode adalah 341 Hari

3. Dengan mengetahui pekerjaan kritis dapat kita tentukan beberapa cara untuk mempercepat pekerjaan tersebut yaitu :

a. Menambah sumber daya, untuk menjalankan proyek agar dapat mencapai tujuan secara efektif dan efisien sangat penting untuk menambah sumber daya apalagi pada pekerjaan yang kritis.

b. Menambah jam kerja ( jam lembur ), dengan menambah jam kerja tentunya dapat membantu mempercepat pekerjaan lebih cepat dikarenakan waktu kerja yang lebih panjang.

\section{SIMPULAN}

1. Berdasarkan pembahasan yang dilakukan pada bab IV, maka diperoleh jalur kritis sebagai berikut : kegiatan AA-AB-AC-AD-BB-CA-CB-DA-DB-DC-DD-DE-DF-AE.

2. Kegiatan yang bersifat kritis berdampak pada waktu penyelesaian proyek secara keseluruhan jika durasi tiap kegiatan tersebut mengalami penundaan.

3. Dengan menggunakan metode Critical Path Methode dapat mempercepat waktu pelaksanaan proyek yang semula selesai dalam 379 hari dapat dipercepat menjadi 341 hari dengan cara menambah sumber daya dan menambah jam kerja ( jam lembur ) kepada pekerjaan-pekerjaan yang kritis.

4. Apabila dalam keadaan tertentu ingin dipercepat waktu pelaksanaannya, maka dengan Network Planning akan mempermudah dalam menentukan kegiatan-kegiatan mana yang harus dipercepat waktu pelaksanannya, misalnya dengan menambah sumber daya atau menambah jam kerja ( kerja lembur ) sehingga keseluruhan dari kegiatan proyek yang ada dapat diselsaikan lebih cepat.

5. Diharapkan nantinya ada penelitian lebih lanjut mengenai perencanaan waktu, biaya, dan sumber daya, pada proyek sejenis yang lebih kompleks.

\section{DAFTAR PUSTAKA}

Badri, S.1997. Dasar-Dasar Network Planing, PT Rika Cipta, Jakarta.

Dannyanti, Eka. 2010. “ Optimalisasi Pelaksanaan Proyek Dengan Metode PERT-

CPM : Studi Kasus Twin Tower Building Pasca Sarjana Undip.

Haedar Ali, Tubagus. 1989. Prinsip-Prinsip Network Planning. Gramedia, Jakarta.

Husen Abrar. 2009. Manajemen Kontruksi Proyek Perencanaan, Penjadwalan dan Pengendalian Proyek. Serpong. Andi.

Kurnia, Arrazaq. 2018. Optimalisasi Pelaksanaan Proyek Dengan Metode CPM

(Critical Path Methode).

Pratasik, Failen,dkk. 2013. Menganalisis Sensitivitas Keterlambatan Durasi Proyek dengan Metode CPM (Studi Kasus : Perumahan Puri Kelapa Gading). Jurnal Sipil Statik Vol.1 No.9,Agustus2013 (603-607) ISSN : 2337-6732.

Santosa, Budi. 2009. Manajemen Proyek: Konsep dan Implementasi.

Graha Ilmu, Yogyakarta.

Soeharto, Iman. 1999. Manajamen Proyek : Dari Konseptual Sampai Operasional. Jakarta : Erlangga

Tjakra, Jermias. Dkk. 2016. "Penerapan Metode CPM Pada Proyek Konstruksi.

Wulfram I. 2005. Manajemen Proyek Konstruksi. Yogyakarta: Andi Offset. 